\title{
Erratum to: Identification of volatile degradation products from Baltic amber by headspace solid-phase microextraction coupled with gas chromatography-mass spectrometry
}

\author{
Gianluca Pastorelli • Jens Glastrup
}

Received: 10 February 2012 / Accepted: 10 February 2012 / Published online: 14 March 2012

(C) Springer-Verlag 2012

\section{Erratum to: Anal Bioanal Chem \\ DOI 10.1007/s00216-010-4424-y}

Dr Jens Glastrup, senior researcher at the Research, Analysis and Consultancy Section of the Department of ConservationNational Museum of Denmark, Kongens Lyngby, Denmark, was inadvertently left off the manuscript as an author when it was submitted to Analytical and Bioanalytical Chemistry.
The co-author Dr Pastorelli now wishes to acknowledge Dr Glastrup as a co-author to correct this oversight.

The co-authors also wish to correct the meaning of the acronym "SIS" mentioned in the article, which is not scientific instruments services, but selected ion storage. The mass spectrometer was tuned, using SIS, to selectively remove $\mathrm{m} / \mathrm{z}$ 28 and 32 from the mass spectra collected.

The online version of the original article can be found at http://dx.doi. org/10.1007/s00216-010-4424-y.

G. Pastorelli $(\bowtie)$

School of Conservation, Royal Danish Academy of Fine Arts,

Esplanaden 34,

1263 Copenhagen K, Denmark

e-mail: g.pastorelli@ucl.ac.uk

G. Pastorelli

Research, Analysis and Consultancy Section of the Department of Conservation, National Museum of Denmark,

IC Modewegsvej, Brede,

2800 Kongens Lyngby, Denmark

\section{J. Glastrup}

Research, Analysis and Consultancy Section

of the Department of Conservation,

The National Museum of Denmark,

IC Modewegsvej, Brede,

Kongens Lyngby 2800, Denmark

Present Address:

G. Pastorelli

The Bartlett School of Graduate Studies - Centre for Sustainable

Heritage, University College London,

Central House, 14 Upper Woburn Place,

London WC1H 0NN, UK 